\title{
The UK Adult Twin Registry (TwinsUK)
}

\author{
Tim D. Spector and Frances M. K. Williams \\ Twin Research and Genetic Epidemiology Unit, Kings College London, St Thomas' Hospital Campus, London, United Kingdom
}

$T^{\text {ne }}$ he UK Adult Twin Registry was started in 1993 and consists of approximately 10,000 monozygotic (MZ) and dizygotic (DZ) adult Caucasian twins aged 16 to 85 years from all over the United Kingdom, plus some parents and siblings. It now incorporates previous twin registries from the Institute of Psychiatry and Aberdeen University. This is a volunteer sample recruited by successive media campaigns without selecting for particular diseases or traits. All twins receive a series of detailed disease and environmental questionnaires. The majority of twins have been assessed in detail clinically at several time points for several hundred phenotypes related to common diseases or intermediate traits. The focus to date has been primarily in 5 areas - cardiovascular, metabolic, musculoskeletal, ophthalmologic diseases as well as the aging process. Over 3000 DZ twins have had a 10cM genome-wide scan performed and 5000 twins tagged for over 200 candidate genes allowing both linkage and association studies. The resource has led to many successful and innovative research projects particularly in common age-related diseases, and has led to collaborations with over 80 groups worldwide.

The UK Adult Twin Registry is a cohort of volunteer adult twins that has evolved rapidly since its inception 15 years ago. Originally, several hundred adult female twins were recruited by media campaign to allow investigation of osteoporosis and osteoarthritis, conditions with higher prevalence in women. The success of these early studies, and the realisation that many traits hitherto considered environmental in aetiology could be investigated, led to expansion of the collection and the inclusion of males. The registry now incorporates twins from the Aberdeen Twin registry and Institute of Psychiatry Adult Registry. The cohort is one of the most highly and deeply phenotyped in the world, and is being enriched by comprehensive genotyping. A description of the scope of the phenotypic collection and the numbers of different samples available and the major research findings is given below.

\section{The Collection}

The twin database now includes over 10,000 twins with an average age of around 45 years and predominantly female and same-sex, because the diseases we initially focused on were more common in women than in men. The ratio of monozygotic (MZ) to dizy- gotic (DZ) twins is approximately 50:50 and the volunteers come from throughout the United Kingdom and Ireland following multiple media campaigns for twins to help with research. The majority of twins have been seen clinically in the unit where clinical tests are performed and blood, urine, DNA and - in a subset -adipose tissue are collected and stored at $-80{ }^{\circ} \mathrm{C}$. Approximately one third of twins have had multiple visits to the unit. The subjects are not paid but are compensated for their travel and accommodation expenses. Zygosity is ascertained using the standard 'Peas in the Pod' questionnaire and where there is uncertainty, zygosity is checked by genotyping. The average clinic visit lasts between 5 and 6 hours. This twin population has been compared for a number of diseases, traits and environmental factors and found to be no different to the UK population or a singleton population cohort from North-East London (Andrew et al., 2001). Full ethical approval has been given for academic and commercial use and consent forms are updated annually and resigned on every visit.

\section{Staff and Facilities}

The unit is situated in the heart of London opposite Big Ben and is nearly exclusively charitable and EU grant-funded with around 40 staff, of whom nine deal with statistical analysis. There is a laboratory that processes and stores over 150,000 biological samples, performs quality control and standardizes concentrations on them with Picogreen. The unit also sends samples to collaborators around the world. We have a (VPN) server that is linked to a common European Twin database. The unit produces regular newsletters for the twins and maintains a website www.twinsUK.ac.uk. The number of twins withdrawing from the cohort averages 175 per year. We replenish the cohort with new twins to maintain the cohort total at around 10,000. Many of the twins have taken part in different studies over the last 10 years. Response rates to questionnaires exceed $75 \%$ and a recent survey of participants attending

\section{Received 30 July, 2006; accepted 10 August, 2006.}

Address for correspondence: Tim D. Spector, Twin Research \& Genetic Epidemiology Unit, St Thomas Hospital Campus, Kings College London, London SE1 7EH, UK. E-mail: tim.spector@kcl.ac.uk 
St Thomas' showed that $95 \%$ were keen to participate further. Contact details of the twins are checked regularly using a variety of computer software packages. In the spring of 2005 we contacted the vast majority of twins by phone and updated their details.

\section{Demographic and Questionnaire Data}

Currently we have data on the following variables for most of the 3500 twin pairs seen:

- height, weight and blood pressure have been recorded at each visit. The mean number of visits is 2.3 per pair

- data relating to metabolic variables have so far been collected from, including body composition (DXA), glucose, insulin and leptin levels

- DNA has been extracted and stored from samples taken from all twins at every visit

- fasting serum, plasma and urine has been isolated, aliquoted and stored from every twin at every visit

- questionnaires completed also record details of drug use, including vitamin consumption (important antioxidants) and hormone replacement therapy (HRT) at every visit

- nutritional data (Epic Food Frequency Questionnaires) have been collected on 6000 twins, analyzed and entered into a database in a collaborative project with the University of East Anglia, Norwich (Professor A. MacGregor).

\section{Biological Samples}

Biological samples form one of the most important sets of phenotypes we collect. These have become increasingly important with the focus towards studying the genetic epidemiology of metabolic and cardiovascular diseases. All the twins who have attended have at least $80 \mathrm{ml}$ of blood collected and we store serum, plasma, urine, extracted DNA, and white blood cells suitable for generating cell-lines. This is because despite using considerable quantities of biological material for studies thus far, extensive efforts are made to replenish the specimen banks (Table 1 ). Serum, urine, plasma EDTA, and plasma Li heparin samples are stored at $-45^{\circ} \mathrm{C}$ at the Twin Research Unit. Back-up samples are stored under similar conditions at St George's Hospital, London in case of natural disasters.

DNA samples and white blood cell RNA and adipose cell RNA (extracted from fat biopsies) are available for selected samples and are stored at $-20{ }^{\circ} \mathrm{C}$. Again, back-up samples are saved elsewhere. DNA samples are available not only for individual twins, but family members, in some cases (Table 1), to enable more extensive family studies. In addition, many of the twin DNA samples have been taken at multiple time points. This has been of benefit in several ways. Firstly, it has ensured a plentiful source

\section{Table 1}

Approximate Numbers of Biological Samples (Single and Multiple Time Point) Stored at the TRU, ECACC and SGH as at June 2006

\begin{tabular}{lc}
\hline Type of specimen & Total number of aliquots stored \\
\hline Serum & 52,000 \\
Plasma EDTA & 34,000 \\
Plasma Li heparin & 9400 \\
Urine & 19,600 \\
Total & 115,000 \\
\hline DNA twins & 11,231 \\
DNA parents & 1000 \\
DNA siblings & 300 \\
Lymphocyte cell lines & 377 \\
Frozen PBL pellets & 6000 \\
Total number of samples & 134,000 \\
\hline
\end{tabular}

of DNA both for studies conducted within the Twin Research Unit and for use by our collaborators. Secondly, as the understanding of the nature of DNA and chromosomes has advanced, it has been extremely useful to have multiple time-point DNA, for example, for telomere length analysis or changes in DNA methylation. A collection of biological material of this size requires considerable housekeeping, maintenance and upkeep; to this end, all laboratory staff are trained in freezer care, freezers are regularly serviced in line with the manufacturers' guidelines, all the freezers are connected to alarm systems in case of temperature failure, and alarms automatically notify laboratory staff at home by phone out of hours.

In addition, we have stored frozen peripheral blood lymphocytes (PBL) at the European Collection of Cell Cultures (ECACC) facility in Porton Down since 2004. These PBLs can be EBV-immortalized at any stage to produce a perpetual source of the donor's DNA. By the end of 2007 this should include most of the 10,000 twins. We currently have 377 transformed cell lines frozen down for immediate use. Collaborations are encouraged and these cell lines are available for use by other groups - see our website for details on how to contact ECACC. In addition, expression data on osteoblasts from six twins is available for collaborator use.

\section{Conventional Phenotypes}

We believe our collection to be one of the most comprehensively phenotyped volunteer samples in the world. It comprises over 1000 clinical phenotypes, ranging from simple demographic data, to detailed hormone profiles (e.g., leptin, homocysteine) and body composition scans. The full list is on our website and Table 2 gives the numbers of these phenotypes, including questionnaire and biological samples above, by medical specialty. 
Table 2

Phenotypes Collected by Specialty

\begin{tabular}{|c|c|c|}
\hline Category grouping & No of phenotypes & Examples \\
\hline Endocrinology, diabetes and metabolism & 307 & Leptin, central fat, fasting insulin \\
\hline Anaesthesia and surgery & 97 & Post-op nausea, operations \\
\hline Microbiology, immunology and allergy & 394 & $\lg \mathrm{E}$, allergies, colds \\
\hline Chest medicine & 72 & FEV1, FVC \\
\hline Pathology and toxicology & 590 & U+Es, LFTs, medications \\
\hline Cardiology & 380 & BP, lipids, angina questionnaire \\
\hline Gastroenterology & 50 & Reflux (GORD), ulcer history, constipation, IBS \\
\hline Neurology & 400 & Cognitive function, memory \\
\hline Oncology & 193 & Breast and bowel cancer \\
\hline Radiology & 250 & Osteoarthritis of hands, hips, knees \\
\hline Rheumatology & 1122 & Soft tissue injuries, bone mineral density, bone markers \\
\hline Dermatology & 310 & Skin type, mole counts \\
\hline Haematology & 272 & Clotting factors, $\mathrm{HbF}$ \\
\hline Ophthalmology & 7 & Myopia, cataract, macular degeneration \\
\hline Urology and nephrology & 52 & Incontinence, UTIs, prostate \\
\hline Obstetrics and gynaecology & 190 & Miscarriages, hysterectomy \\
\hline Ear, nose, throat, oral and dental & 75 & Deafness, pitch perception, tooth loss \\
\hline
\end{tabular}

\section{Novel Molecular Phenotypes}

Over the last year we have conducted a number of preliminary studies exploring the use of innovative techniques and extending the range of studies in which twins can play a powerful role as part of the EU Molpage consortium. These include comparing twins for differences in gene expression, proteomics, peptidomics, and metabonomics.

\section{$\overline{\text { Aims }}$}

The overall objectives of the unit are: (1) to estimate heritabilities for common diseases and traits in adults, (2) discover genes that influence these traits using linkage and association, (3) provide a framework for epidemiologic studies using the twin design, (4) develop statistical methodology to facilitate these aims, and (5) collaborate with other groups and promote the wide use of the data.

\section{Major Research Findings to Date}

The following groupings are examples of major research findings using the twin registry, but are not intended as an exhaustive list.

\section{Osteoporosis}

- the following risk factors for osteoporotic fracture are strongly and independently genetic: bone density, bone quality (BUA), hip axis length, vitamin D levels, bone turnover markers, muscle strength (Arden et al., 1996)

- vitamin D receptor, TGF Beta, Klotho, PDE4 genotypes are associated with bone density (Keen et al., 1997)
- skeletal size is associated with birthweight in discordant twins (Antoniades et al., 2003)

- quantitative trait loci (QTLs) isolated for bone mineral density (BMD), bone quality and bone turnover (Wilson et al., 2003)

- gene expression differences in osteoblasts of discordant MZ twins (Mak et al., 2004).

\section{Osteoarthritis/Spine}

- osteoarthritis of knee, hand and hip, spine all strongly heritable (Spector \& Macgregor, 2004)

- some overlapping shared genes with osteoporosis (Antoniades et al., 2000)

- lumbar disc disease heritable, as is low back pain (Sambrook et al., 1999)

- multiple candidate genes replicated with knee disease (Valdes et al., 2006)

- obesity and osteoarthritis genes are not shared (Manek et al., 2003)

- replicated QTL found for hand osteoarthritis (Livshits et al., in press).

\section{Metabolic Syndrome}

- central fat deposition and body shape is genetic (Samaras et al., 1997)

- HRT and cigarette use reduces central fat and total body fat (Samaras et al., 1998)

- leptin is correlated genetically with adiposity and body size (Chen et al., 2005)

- HbA1C levels reflect genetic susceptibility more than consequence of disease (Snieder et al., 2001) 
- QTLs detected for total and central obesity (Wilson et al., 2006).

\section{Cardiovascular disease}

- QT and PR interval, pulse rate, BP and arterial resistance all show genetic influence (Snieder et al., 2000)

- blood pressure in adults related to birthweight (Poulter et al., 1999)

- replication of QTLs for BP and hypertension (de Lange et al., 2004)

- major clotting factors and fibrin strongly heritable (de Lange et al., 2001)

- QTLs and genetic variants for Factor XIII gene uncovered (de Lange et al., 2006)

- lipids levels heritable and with significant replicated QTLs (Falchi et al., 2005)

- hypertension, migraine, Raynaud's and cardiovascular disease have a shared genetic influence (Williams et al., 2004).

\section{Skin Disease and Atopy}

- freckles and naevi strongly heritable with little environmental influence (Bataille et al., 2000)

- acne strongly genetic (Bataille et al., 2002)

- eczema and hayfever heritable with some shared genes (Strachan et al., 2001)

- replication of QTLs for naevus counts (Falchi et al., 2006).

\section{Eye Disease}

- myopia and presbyopia, cataract, squint, early macular degeneration and pupil dilation all strongly heritable (Hammond et al., 2000)

- QTLs and candidate genes discovered for myopia and cataract (Hammond et al., 2004).

\section{Immune and Haemopoetic System}

- levels of white and red cells and platelets heritable (Hall et al., 2000)

- levels of circulating hemoglobin $\mathrm{F}$ heritable and related to specific polymorphisms (Garner et al., 2000)

- CD4 and CD8 circulating T cells under genetic influence (Ahmadi et al., 2001)

- X inactivation has genetic basis (Vickers et al., 2001)

- QTL on chromosome 8q influences the switch from fetal to adult hemoglobin. (Garner et al., 2004)

- cMYB regulates fetal haemoglobin (Jiang et al., 2006)

\section{Miscellaneous}

- cognitive component of humor influenced by family environment (Cherkas et al., 2000)
- pitch recognition is strongly genetic (Drayna et al., 2001)

- timing of menarche and menopause strongly genetic but not related (Snieder et al., 1998)

- Raynaud's phenomenon and cold intolerance are genetic (Cherkas et al., in press)

- twins are comparable to singletons for most common traits measured (Andrew et al., 2001)

- telomere length in white cells heritable and shows significant QTLs in linkage (Andrew et al., 2006)

- telomere length is related to smoking, obesity and social class (Valdes et al., 2005).

We have confirmed the effectiveness of the twin study design in our own cohort by being able to explore both linkage and association for a number of traits, including myopia, obesity, memory, bone density and lipid levels.

\section{The Co-Twin Case-Control Design}

Phenotypic differences between MZ twins are accounted for mainly by environmental differences as well as epigenetic factors. Carrying out case-control studies in MZ twins that are either discordant for environmental exposures or phenotypic traits, provides a naturally matched case-control study design in which pairs are matched for their age, sex, nurture as well as their genetic background. Over the past 12 years we have collected a large range of environmental exposures in our twins (including smoking, alcohol, diet, exercise, drug use, education, employment, social class, and so on).

These can be used to study (a) environmental exposures, (b) pharmacological intervention and (c) disease mechanisms.

(a) Examples of our studies investigating environmental exposures include:

- HRT on bone

- physical activity in obesity

- smoking in skin aging

- alcohol intake on bone density

- obesity on $\mathrm{C}$ reactive protein.

(b) A variation of this design has been used by us to examine pharmacological intervention in a rigorously matched setting:

- vitamin D supplementation that had no influence on bone mineral density in normal postmenopausal women

- an ongoing Wellcome Trust funded trial of nutritional supplements to prevent macular degeneration.

(c) Examples into disease mechanisms include:

- The mechanism of X-chromosome inactivation is poorly understood but involves methylation. We found the skewness of granulocyte $\mathrm{X}$ inactivation 
had a heritable component of $68 \%$, a few MZ pairs displayed opposite skewing patterns suggesting stochastic mechanisms in operation.

- Differential transmission of mitochondrial DNA in $\mathrm{MZ}$ twins allows specific mitochondrial gene mutations to be studied and studying mutation rates in our $\mathrm{MZ}$ twins provided an approach to dating evolutionary change.

- Functional MRI studies of the brain in discordant handed MZ twin pairs have implicated important developmental areas.

- Studies of gene expression in MZ twins provide an efficient approach for identifying the specific genes that are expressed in diseased individuals. Using bone biopsies we studied osteoblast expression differences between members of osteoporosis discordant MZ pairs. This provided a cluster of candidate genes.

- Subtle epigenetic methylation changes and differences - not present at birth - can be detected in pairs of elderly MZ twins (Fraga et al., 2005). We found these changes increased with environmental diversity and were seen in fat as well as muscle and white blood cell DNA. Once true functional genes are discovered $\mathrm{MZ}$ twin studies can potentially be used to give information on the penetrance of risk genes, although we don't yet have firm examples.

- Theories about fetal programming influencing subsequent adult susceptibility to disease can be tested in twins. This design controls for important maternal influences such as smoking and social class. We have used this approach to show a small but significant association between birthweight and adult blood pressure and between birthweight and adult bone mass.

\section{Examples of Current Large-Scale Clinical Project Twin Grants}

1. an FGI biobank collecting DNA, serum and urine from all 10,000 twins on the database to establish a national biological resource (Wellcome Trust)

2. a core program grant to maintain the Twin biobank and facilitate collaborations (Wellcome Trust)

3. a trial in twins of nutrients to prevent macular degeneration (Wellcome Trust)

4. a linkage study of QTLs for myopia (Wellcome)

5. a study examining bone loss and arterial calcification in twins (British Heart Foundation)

6. an ARC funded study looking at the genetics of pain perception in twins

7. a BBSRC grant looking at genes for height and weight and skeletal ratios using and developing new haplotype tagging methods

8. an EC Framework VI study (EuroClot - as coordinating centre) to identify the major genes involved in end-stage clotting using twin cohorts from countries across Europe.

9. an EC Framework VI study (MolPAGE- as participant) supplying most of the clinical material for the study of molecular phenotypes for obesity and Type 2 diabetes.

10. an EU Framework V (GenomEUtwin //www. genomeutwin.helsinki.fi/) project linking eight European twin registries and aiming to identify genes for stature, weight, migraine and heart disease.

\section{Future Work and Genotype Information}

- focus on age-related traits and diseases and longitudinal changes of these traits and diseases

- genome-wide association scan of 317,000 single nucleotide polymorphisms (SNP) markers (Illumina 300 Hapchip) will be performed on 2000 twins by the Sanger Centre commencing in October 2006

- aim to perform more linkage scans and extend the marker set to 2000 pairs

- we will perform a combination of linkage and association studies to narrow down the loci of interest and use disequilibrium mapping to pin down the key genes

- further gene expression work planned using other tissues, blood, skin and fat

- we have worked with a large number of different collaborators in the past and we are keen to encourage further and future collaborations particularly in areas where we can gain from additional clinical or technical expertise or where groups can add phenotypic or genotypic information.

\section{Funding Sources}

Wellcome Trust, European Union, British Heart Foundation, Arthritis Research Campaign, National Institutes of Health, Guide Dogs for the Blind, Chronic Disease Research Fund.

\section{Most Important Twin Unit Publications See website for full listing}

Ahmadi, K. R., Hall, M. A., Norman, P., Vaughan, R. W., Snieder, H., Spector, T. D., \& Lanchbury, J. S. (2001). Genetic determinism in the relationship between human CD4+ and CD8+ T lymphocyte populations? Genes and Immunity, 2, 381-387.

Andrew, T., Aviv, A., Falchi, M., Surdulescu, G. L., Gardner, J. P., Lu, X., Kimura, M., Kato, B. S., Valdes, A. M., \& Spector, T. D. (2006). Mapping genetic loci that determine leukocyte telomere length in a large sample of unselected female sibling pairs. American Journal of Human Genetics, 78, 480-486.

Andrew, T., Hart, D. J., Snieder, H., de Lange, M., Spector, T. D., \& Macgregor, A. J. (2001). Are twins and singletons comparable? A study of disease-related and lifestyle 


\section{Twins UK Register, St Thomas Hospital Update}

\begin{tabular}{|c|c|c|}
\hline Name of register & \multicolumn{2}{|c|}{ UK Adult Twin Registry (TwinsUK) } \\
\hline Country & \multicolumn{2}{|c|}{ United Kingdom } \\
\hline Kind of ascertainment & \multicolumn{2}{|c|}{ Volunteers unselected } \\
\hline Opposite-sex twins (yes or no) & \multicolumn{2}{|l|}{ Yes } \\
\hline \multirow[t]{8}{*}{$\begin{array}{l}\text { Number of pairs } \\
\text { (separated by birth range and sex) }\end{array}$} & 1900-1920: & $\begin{array}{l}10 \mathrm{FF} \\
3 \mathrm{MM}\end{array}$ \\
\hline & 1920-1930: & $\begin{array}{l}144 \mathrm{FF} \\
20 \mathrm{MM}\end{array}$ \\
\hline & 1930-1940: & $\begin{array}{l}670 \mathrm{FF} \\
79 \mathrm{MM}\end{array}$ \\
\hline & 1940-1950: & $\begin{array}{l}1074 \mathrm{FF} \\
115 \mathrm{MM}\end{array}$ \\
\hline & 1950-1960: & $\begin{array}{l}937 \mathrm{FF} \\
193 \mathrm{MM}\end{array}$ \\
\hline & 1960-1970: & $\begin{array}{l}743 \mathrm{FF} \\
193 \mathrm{MM}\end{array}$ \\
\hline & 1970-1980: & $\begin{array}{l}510 \mathrm{FF} \\
157 \mathrm{MM}\end{array}$ \\
\hline & 1980-2000: & $\begin{array}{l}141 \mathrm{FF} \\
31 \mathrm{MM}\end{array}$ \\
\hline \multirow[t]{3}{*}{ Totals } & \multicolumn{2}{|l|}{$4222 \mathrm{FF}$} \\
\hline & \multicolumn{2}{|l|}{$788 \mathrm{MM}$} \\
\hline & \multicolumn{2}{|l|}{$118 \mathrm{FM}$} \\
\hline Grand total & \multicolumn{2}{|l|}{5488 pairs } \\
\hline Major interests & \multicolumn{2}{|c|}{ Common complex diseases and traits } \\
\hline Traits measured & \multicolumn{2}{|c|}{$\begin{array}{l}\text { Full questionnaires and clinical exam and testing on majority of twins for wide range of over } 1000 \text { clinical } \\
\text { and biochemical traits including: cardiovascular disease, obesity, metabolic syndrome, respiratory } \\
\text { disease, dermatology, osteoarthritis, osteoporosis, eye disease, back disease, coagulation system, } \\
\text { immune function, cognitive function, gastro-intestinal system, pain thresholds, allergy, atopy, sexuality, } \\
\text { pitch perception, sense of humor. }\end{array}$} \\
\hline DNA samples & \multicolumn{2}{|l|}{6649} \\
\hline \multirow[t]{2}{*}{ Various samples } & \multicolumn{2}{|l|}{6700 serum } \\
\hline & \multicolumn{2}{|l|}{6500 urine } \\
\hline Contact & \multicolumn{2}{|l|}{ Tim Spector } \\
\hline Address & \multicolumn{2}{|c|}{ Twin Research Unit, St. Thomas' Hospital, London SE1 7EH } \\
\hline e-mail & \multicolumn{2}{|c|}{ Tim.spector@kcl.ac.uk or victoria.vazquez@kcl.ac.uk } \\
\hline Website & \multicolumn{2}{|c|}{ www.TwinssUk.ac.uk } \\
\hline Main recent twin publications & \multicolumn{2}{|c|}{ See references and www.twinsUk.ac.uk for PDFs } \\
\hline Main sources of funding & \multicolumn{2}{|c|}{ Wellcome Trust, EU, ARC, British Heart Foundation, CDRF, } \\
\hline Comments & \multicolumn{2}{|c|}{ MZ:DZ ratio approximately $1: 1$} \\
\hline & \multicolumn{2}{|c|}{ Database majority female mean age 50.} \\
\hline & \multicolumn{2}{|c|}{1500 pairs with full genome linkage scan information } \\
\hline & \multicolumn{2}{|c|}{2000 with genome-wide association data by the end of 2007} \\
\hline
\end{tabular}

Note: $F F=$ female-female

$\mathrm{MM}=$ male-male

$\mathrm{FM}=$ female - male

characteristics in adult women. Twin Research, 4, 464-477.

Antoniades, L., Macgregor, A. J., Andrew, T., \& Spector, T. D. (2003). Association of birth weight with osteoporosis and osteoarthritis in adult twins. Rheumatology, 42, 791-796.

Antoniades, L., Macgregor, A. J., Matson, M., \& Spector, T. D. (2000). A cotwin control study of the relationship between hip osteoarthritis and bone mineral density. Arthritis and Rheumatism, 43, 1450-1455.

Arden, N. K., Baker, J., Hogg, C., Baan, K., \& Spector, T. D. (1996). The heritability of bone mineral density, ultrasound of the calcaneus and hip axis length: a study of postmenopausal twins. Journal of Bone and Mineral Research, 11, 530-534.

Ariens, R. A., de Lange, M., Snieder, H., Boothby, M., Spector, T. D., \& Grant, P. J. (2002). Activation markers 
of coagulation and fibrinolysis in twins: Heritability of the prethrombotic state. Lancet. 359, 667-671.

Bataille, V., Snieder, H., Macgregor, A. J., Sasieni, P., \& Spector, T. D. (2000). Genetics of risk factors for melanoma: an adult twin study of nevi and freckles. Journal of the National Cancer Institute, 92, 457-463.

Bataille, V., Snieder, H., Macgregor, A. J., Sasieni, P., \& Spector, T. D. (2002). The influence of genetics and environmental factors in the pathogenesis of acne: A twin study of acne in women. Journal of Investigative Dermatology, 119, 1317-1322.

Chen, Y., Snieder, H., Wang, X., Kaviya, B., McCaffrey, C., Spector, T. D., Carter, N. D., \& O’Dell, S. D. (2005). Proopiomelanocortin gene variants are associated with serum leptin and body fat in a normal female population. European Journal of Human Genetics, 13, 772-780.

Cherkas, L., Hochberg, F., Macgregor, A. J., Snieder, H., \& Spector, T. D. (2000). Happy families: A twin study of humour. Twin Research, 3, 17-22.

Cherkas, L., Williams, F., Carter, L., Black, C., Spector, T. D., \& Macgregor, A. J. (in press). Raynauds phenomenon and vascular responsiveness to cold: A study of adult female twins. Arthritis Rheumatism.

de Lange, M., Andrew, T., Snieder, H., Ge, D., Futers, T. S., Standeven, K., Spector, T. D., Grant, P. J., \& Ariens, R. A. (2006). Joint linkage and association of six singlenucleotide polymorphisms in the factor XIII-A subunit gene point to V34L as the main functional locus. Arteriosclerosis, Thrombosis, and Vascular Biology, 26, 1914-1919.

de Lange, M., Snieder, H., Ariens, R. A., Spector, T. D., \& Grant, P. J. (2001). The genetics of haemostasis: A twin study. Lancet, 357, 101-105.

de Lange, M., Spector, T. D., \& Andrew, T. (2004). Genome-wide scan for blood pressure suggests linkage to chromosome 11 , and replication of loci on 16,17 , and 22. Hypertension, 44, 872-877.

Drayna, D., Manichaikul, A., de Lange, M., Snieder, H., \& Spector, T. (2001). Genetic correlates of musical pitch recognition in humans. Science, 291, 1969-1972.

Falchi, M., Andrew, T., Snieder, H., Swaminathan, R., Surdulescu, G. L., \& Spector, T. D. (2005). Identification of QTLs for serum lipid levels in a female sib-pair cohort: A novel application to improve the power of two-locus linkage analysis. Human Molecular Genetics, 14, 2971-2979.

Falchi, M., Spector, T. D., Perks, U., Kato, B. S., \& Bataille, V. (2006). Genome-wide search for nevus density shows linkage to two melanoma loci on chromosome 9 and identifies a new QTL on 5q31 in an adult twin cohort. Human Molecular Genetics. [Epub ahead of print].

Fraga, M., Ballestar, E., Paz, M. F., Ropero, S., Setien, F., Ballestar, M. L., Heine-Suner, D., Cigudosa, J. C., Urioste, M., Benitez, J., Boix-Chornet, M., SanchezAguilera, A., Ling, C., Carlsson, E., Poulsen, P., Vaag, A., Stephan, Z., Spector, T. D., Wu, Y., Plass, C., \&
Esteller, M. (2005). Epigenetic differences arise during the lifetime of monozygotic twins. Proceedings of the National Academy Science USA, 102, 10604-10609.

Garner., C., Silver, N., Best, S., Menzel, S., Martin, C., Spector, T. D., \& Thein, S. L. (2004). QTL on chromosome $8 \mathrm{q}$ influences the switch from fetal to adult hemoglobin. Blood, 104, 2184-2186.

Garner, C., Tatu, T., Reittie, J. E., Littlewood, T., Darley, J., Cervino, S., Farrall, M., Kelly, P., Spector, T. D., \& Thein, S. L. (2000). Genetic influences on F cells and other hematologic variables: A twin heritability study. Blood, 95, 342-346.

Hall, M. A., Ahmadi, K. R., Norman, P., Snieder, H., Macgregor, A. J., Vaughan, R. W., Spector, T. D., \& Lanchbury, J. S. (2000). Genetic influence on peripheral blood T lymphocyte levels. Genes and Immunity, 1, 423-427.

Hammond, C. J., Andrew, T., Mak, Y. T., \& Spector, T. D. (2004). A susceptibility locus for myopia in the normal population is linked to the PAX6 gene region on chromosome 11: A genomewide scan of dizygotic twins. American Journal of Human Genetics, 75, 294-304.

Hammond, C. J., Snieder, H., Spector, T. D., \& Gilbert, C. E. (2000). Genetic and environmental factors in agerelated nuclear cataracts in monozygotic and dizygotic twins. New England Journal of Medicine, 342, 1786-1790.

Jiang, J., Best, S., Menzel, S., Silver, N., Lai, M. I., Surdulescu, G. L., Spector, T. D., \& Thein, S. L. (2006). cMYB is involved in the regulation of fetal hemoglobin production in adults. Blood, 108, 1077-1083.

Keen, R. W., Egger, P., Fall, C., Major, P. J., Lanchbury, J. S., Spector, T. D., \& Cooper, C. (1997). Polymorphisms of the vitamin D receptor, infant growth, and adult bone mass. Calcified Tissue International, 60, 233-235.

Livshits, G., Kato, B., Zhai, G., Hart, D. J., Hunter, D., Williams, F., MacGregor, A., \& Spector, T. D. (in press). Genomewide linkage scan of hand osteoarthritis in female twin pairs showing replication of QTLs on chromosome 2 and 19. Annals of the Rheumatic Diseases.

Mak, Y. T., Hampson, G., Beresford, J. N., \& Spector, T. D. (2004). Variations in genome-wide gene expression in identical twins - A study of primary osteoblast-like culture from female twins discordant for osteoporosis. BMC Genetics, 5, 14.

Manek, N. J., Hart, D., Spector, T. D., \& Macgregor, A. J. (2003). The association of body mass index and osteoarthritis of the knee joint: An examination of genetic and environmental influences. Arthritis and Rheumatism, 48, 1024-1029.

Poulter, N. R., Chang, C. L., Macgregor, A. J., Snieder, H., \& Spector, T. D. (1999). Association between birth weight and adult blood pressure in twins: historical cohort study. British Medical Journal, 319, 1330-1333.

Samaras, K., Kelly, P. J., Spector, T. D., Chiano, M. N., \& Campbell, L. V. (1998). Tobacco smoking and oestrogen replacement are associated with lower total and central 
fat in monozygotic twins. International Journal of Obesity and Related Metabolic Disorders, 22, 149-156.

Samaras, K., Spector, T. D., Nguyen, T. V., Baan, K., Campbell, L. V., \& Kelly, P. J. (1997). Independent genetic factors determine the amount and distribution of fat in women after the menopause. Journal of Clinical Endocrinology and Metabolism, 82, 781-785.

Sambrook, P. N., Macgregor, A. J., \& Spector, T. D. (1999). Genetic influences on cervical and lumbar disc degeneration: A magnetic resonance imaging study in twins. Arthritis and Rheumatism, 42, 366-372.

Snieder, H., Hayward, C. S., Perks, U., Kelly, R. P., Kelly, P. J., \& Spector, T. D. (2000). Heritability of central systolic pressure augmentation: A twin study. Hypertension, 35, 574-579.

Snieder, H., Macgregor, A. J., \& Spector, T. D. (1998). Genes control the cessation of a woman's reproductive life: A twin study of hysterectomy and age at menopause. Journal of Clinical Endocrinology and Metabolism, 83, 1875-1880.

Snieder, H., Sawtell, P. A., Ross, L., Walker, J., Spector, T. D., \& Leslie, R. D. (2001). HbA(1c) levels are genetically determined even in type 1 diabetes: Evidence from healthy and diabetic twins. Diabetes, 50, 2858-2863.

Spector, T. D., \& Macgregor, A. J. (2004). Risk factors for osteoarthritis: Genetics. Osteoarthritis Cartilage, 12(Suppl. A), p. S39-S44.

Strachan, D. P., Wong, H. J., \& Spector, T. D. (2001). Concordance and interrelationship of atopic diseases and markers of allergic sensitization among adult female twins. Journal of Allergy and Clinical Immunology, 108, 901-907.
Valdes, A. M., Andrew, T., Gardner, J. P., Kimura, M., Oelsner, E., Cherkas, L. F., Aviv, A., \& Spector, T. D. (2005). Obesity, cigarette smoking, and telomere length in women. Lancet, 366, 662-664.

Valdes, A. M., Van Oene, M., Hart, D. J., Surdulescu, G. L., Loughlin, J., Doherty, M., \& Spector, T. D. (2006). Reproducible genetic associations between candidate genes and clinical knee osteoarthritis in men and women. Arthritis and Rheumatism, 54, 533-539.

Vickers, M. A., McLeod, E., Spector, T. D., \& Wilson, I. J. (2001). Assessment of mechanism of acquired skewed X inactivation by analysis of twins. Blood, 97, 1274-1281.

Williams, F. M., Cherkas, L. F., Spector, T. D., \& Macgregor, A. J. (2004). A common genetic factor underlies hypertension and other cardiovascular disorders. BMC Cardiovascular Disorders, 4, 20.

Wilson, S. G., Adam, G., Langdown, M., Reneland, R., Braun, A., Andrew, T., Surdulescu, G. L., Norberg, M., Dudbridge, F., Reed, P. W., Sambrook, P. N., Kleyn, P. W., \& Spector, T. D. (2006). Linkage and potential association of obesity-related phenotypes with two genes on chromosome $12 \mathrm{q} 24$ in a female dizygous twin cohort. European Journal of Human Genetics, 14, 340-348.

Wilson, S. G., Reed, P. W., Bansal, A., Chiano, M., Lindersson, M., Langdown, M., Prince, R. L., Thompson, D., Thompson, E., Bailey, M., Kleyn, P. W., Sambrook, P., Shi, M. M., \& Spector, T. D. (2003). Comparison of genome screens for two independent cohorts provides replication of suggestive linkage of bone mineral density to $3 \mathrm{p} 21$ and $1 \mathrm{p} 36$. American Journal of Human Genetics, 72, 144-155. 